\title{
Viabilidade para a Instalação de um Hotel em Missão Velha-CE
}

\author{
Rozires Silva dos Santos ${ }^{1}$; Wesley Barros Viana ${ }^{2}$; Manoel Leal Costa Netto ${ }^{3}$
}

\begin{abstract}
Resumo: O presente estudo procurou como objetivo geral, investigar a viabilidade econômica e financeira de um empreendimento no ramo hoteleiro na cidade de Missão Velha-CE, ponderando as características e dados que se referem ao mercado local, para estabelecer de forma segura as estratégias para a implantação do hotel, sendo realizada a análise de mercado local. De maneira metodológica, foi realizada uma pesquisa de opinião pública com cunho descritivo e exploratório, com abordagem quantitativa. A pesquisa foi aplicada ao público participante entre os dias 06 e 08 de novembro de 2018. Utilizou-se de um questionário com 09 perguntas, distribuídas entre abertas e fechadas. Foram aplicadas por intermédio do Google Forms Questionários. Em seguida com os dados coletados, ocorreu a tabulação pelo auxílio do software Excel. Com resultados obtidos, conclui-se que existe uma viabilidade positiva para a instalação do empreendimento na cidade citada. Percebeu-se também que os clientes desejam qualidade, limpeza, segurança e bom preço nos serviços ofertados pelos hotéis, bem como outros aspectos relevantes, que podem ser usados como diferencial competitivo.
\end{abstract}

Palavras-Chave: Empreendedorismo. Hotelaria. Viabilidade.

\section{Feasibility for the Installation of a Hotel in the city of Missão Velha, Ceará State}

\begin{abstract}
The present study sought as general objective, to investigate the economical and financial viability of an enterprise in the hotel branch in the city of Mission Old-CE, considering the characteristics and data that refer to the local market, to establish in a safe way the strategies for the implantation of the hotel, being accomplished the analysis of local market. In a methodological way, a research of public opinion was accomplished with descriptive and exploratory stamp, with quantitative approach. The research was applied the participant public between the 06 and November 08 of 2018. it was used of a questionnaire with 09 questions, distributed between open and closed. They were applied through Google Forms Questionnaires. Soon afterwards with the collected data, it happened the tabulation for the I aid of the software Excel. With obtained results, it is ended that a positive viability exists for the installation of the enterprise in the mentioned city. It was also noticed that the customers want quality, cleaning, safety and good price in the services presented by the hotels, as well as other relevant aspects, that can be used as differential competitive.
\end{abstract}

Keywords: Entrepreneurship. Hospitality. Viability.

\section{Introdução}

Este estudo de viabilidade é um documento que relata de forma escrita os objetivos do empreendimento Hotel Os Britos e quais passos serão necessários para que os objetivos sejam

\footnotetext{
${ }^{1}$ Graduanda em administração, Centro Universitário Doutor Leão Sampaio, Juazeiro do Norte, Ceará, Brasil. Contato: rozires.silva08@hotmail.com

${ }^{2}$ Graduando em administração, Centro Universitário Doutor Leão Sampaio, Juazeiro do Norte, Ceará, Brasil. Contato: weslley_barros19@hotmail.com

${ }^{3}$ Professor orientador, Centro Universitário Doutor Leão Sampaio, Juazeiro do Norte, Ceará, manoel@ leaosampaio.edu.br 
alcançados, reduzindo as incertezas e os riscos. Este referido documento irá permitir que seja identificado e restringido os erros, antes de cometidos no mercado, realizando assim uma prevenção.

A atual globalização promove dificuldades para quem deseja ser empreendedor, pois a concorrência vem aumentando com o passar do tempo. Para iniciar um negócio precisa-se conhecer o produto que deseja vender, sendo esse um dos primeiros atos a ser executados, visto que serão necessários estudos, pesquisa, análise e planejamento (SEBRAE, 2016). Os fatores contribuintes para a sobrevivência/mortalidade das empresas são: Planejamento do negócio, gestão do negócio e capacitação dos donos em gestão empresarial.

Para que no empreendimento não ocorram nenhum erro, a elaboração deste estudo de viabilidade é indispensável, podendo ser possível o conhecimento profundo em relação ao negócio, clientes, fornecedores, concorrentes, tendências futuras e a situação financeira no que se refere ao caixa.

Tendo em vista o pressuposto, qual a probabilidade e a viabilidade de implantar um hotel em Missão Velha - Ceará? Para responder esta problemática, este estudo tem por objetivo geral investigar a viabilidade econômica e financeira de um empreendimento no ramo da hotelaria na cidade de Missão Velha-CE, ponderando as características e dados referentes ao mercado local. De modo específico, visa estabelecer de forma segura, estratégias para a implantação de um hotel; analisar o mercado hoteleiro local e suas potencialidades e organizar um plano financeiro, marketing e operacional.

O referido estudo justifica-se pelo interesse pessoal de desenvolver uma ação empreendedora na cidade citada, considerando o fluxo de viajantes da região Cariri, tendo como atrativo as boas rotas e rodovias do eixo Juazeiro do Norte, Barbalha e Missão Velha, destacando ainda uma baixa concorrência local. Justifica-se também como respaldo acadêmico, julgando ser fonte de pesquisa para futuros trabalhos, visto os aspectos inerentes ao referencial teórico. Em termos sociais, apresenta a possibilidade de geração de renda, caso a visibilidade da implantação seja positiva.

\section{Referencial Teórico}

O tópico a seguir destina-se a apresentar o referencial teórico usado, com o intuito de fundamentar este estudo. Foi realizado uma revisão com característica ampla e variada, com o objetivo de apresentar os principais conceitos aplicáveis ao contexto do documento analisado. 


\section{Empreendedorismo}

Qualquer negócio possuirá no mínimo uma pessoa com a responsabilidade de planejar e executar as ações do empreendimento. Esta pessoa é o empreendedor que vislumbra a oportunidade e dá início ao negócio, procurando retorno financeiro de forma concreta, considerando os riscos de maneira planejada (DORNELAS, 2005).

O empreendedor promove uma transformação na estrutura econômica que existe até então, por meio da inovação em produtos e/ou serviços, formas de organização e exploração diferenciada de recursos e materiais que até então estavam ocultos (DORNELAS, 2008). O mesmo autor citado aponta que o indivíduo empreendedor percebe o processo de mudança e oportunidades a sua volta, almejando na sequência desenvolver e manter transformações constantes para reagindo às incertezas do mercado.

Além disso, é uma característica importante para pessoas empreendedoras, à persistência por entender que alguns fracassos são oportunidade de ganhar experiência com erros cometidos, apontando também à dedicação aos objetivos propostos, seguindo as metas estabelecidas com fidelidade (DORNELAS, 2008). Segundo Bernardi (2013) não é possível apontar a certeza de um indivíduo obter sucesso com o negócio, afinal liderar um empreendimento exige habilidades e competências, salientando ainda as circunstâncias e motivações para o empreendedor, como descritas no quadro 01 .

Quadro 01: Circunstâncias e motivações para o empreendedorismo.

\begin{tabular}{|c|l|}
\hline Empreendedor nato & $\begin{array}{l}\text { Personalização integral de empreendedor. Tal vocação tem forte relação com o tipo de } \\
\text { autoridade familiar e ambiente familiar, tais como escala de valores e percepção de } \\
\text { negócios. }\end{array}$ \\
\hline Herdeiro & $\begin{array}{l}\text { Pode possuir ou não as características do empreendedor. Se empreendedor por } \\
\text { afinidade e vocação, dá continuidade ao empreendimento em que se encontra desde } \\
\text { muito cedo em treinamento, o que é muito comum. Não tendo características } \\
\text { empreendedoras e "treinado", pode tornar-se um problema para a empresa. }\end{array}$ \\
\hline Funcionário da empresa & $\begin{array}{l}\text { Possuindo características empreendedoras, sente frustração ao longo da carreira, seja } \\
\text { pela falta de reconhecimento das suas ideias ou pela interferência da burocracia. Em } \\
\text { algum momento da carreira, resolve partir para um negócio próprio. }\end{array}$ \\
\hline Excelente técnico & $\begin{array}{l}\text { Com características empreendedoras e know-how sobre determinado produto ou } \\
\text { serviço, resolve iniciar um negócio próprio. }\end{array}$ \\
\hline Vendedor & $\begin{array}{l}\text { Entusiasmado pela dinâmica de sua função, opta por iniciar o negócio no mercado que } \\
\text { tem experiência. }\end{array}$ \\
\hline Opção ao desemprego & $\begin{array}{l}\text { Modalidade arriscada. Tendo características empreendedoras há possibilidade de } \\
\text { sucesso. Não as tendo, suas possibilidades de sucesso acabam ligadas diretamente à } \\
\text { forma como encara a oportunidade. }\end{array}$ \\
\hline Desenvolvimento paralelo & $\begin{array}{l}\text { Tendo características empreendedoras, funcionário, como alternativa futura, se } \\
\text { estrutura com amigos ou familiares e desenvolve negócio na sua área de conhecimento } \\
\text { ou não, atuando como sócio capitalista. }\end{array}$ \\
\hline Aposentadoria & $\begin{array}{l}\text { Devido à precocidade de idade com que o mercado de trabalho marginaliza as pessoas, } \\
\text { inicia seu próprio negócio. }\end{array}$ \\
\hline
\end{tabular}

Fonte: Adaptado de Bernardi (2013). 


\section{Planejamento}

O ato de planejar como é quando se define os objetivos e as melhores estratégias para atingi-los, perguntas como: Aonde se quer chegar? Como vai ser feito? Quando começará ou quanto durará? E quais a sequência as ações ocorrerá? São respondidas ao longo de um bom planejamento estratégico.

Existiram três tipos de planejamento: Estratégico, tático e operacional. Em resumo, elas iram se diferenciar em relação à quantidade de informações sobre o negócio e em relação ao tempo que o planejamento abrangerá. Para Chiavenato (2014) o estratégico está relacionado às decisões tomadas a serem executadas. O tático é o gerenciamento destas estratégias tomadas. Já o operacional é a execução das descrições.

O planejamento se traduz na busca do futuro de maneira planejada e também da utilização dos meios eficientes para alcançar os objetivos que foram definidos. Onde as previsões feitas se tornaram realidade pela probabilidade que foi anteriormente analisada, seguida da realização das tarefas que foram planejadas no presente (DORNELAS, 2005).

O direcionamento dos esforços, por intermédio do planejamento, acrescenta um rumo ao negócio, traçando objetivos e prevenindo algumas situações desagradáveis. Ressaltando que o planejamento é fundamental, principalmente quando é levado em conta a dinâmica do setor empresarial, a variabilidade e complexidade deste (CHIAVENATO, 2014).

\section{Plano de Negócios}

O plano de negócio é um documento que irá descrever de forma oficial os objetivos que foram planejados para o empreendimento, onde irá descrever o caminho a ser percorrido, pontuando os objetivos a serem atingidos, a busca da redução ao máximo dos riscos e o estudo das incertezas inerentes ao negócio (SEBRAE, 2013).

Para fixar ainda mais a importância deste documento os autores Hirsch e Peters (2004), afirmam que o plano de negócio é de suma importante, tendo em vista que descreve o início do empreendimento, auxilia a determinar a viabilidade do negócio dentro de um mercado específico, possibilita orientar o indivíduo empreendedor quando há necessidade de organizar atividades de planejamento e aponta as origens dos recursos financeiros necessários para aplicação no negócio. 
Nogueira e Almeida (2011) mencionam que o plano de negócio é um conjunto de dados e informações sobre o negócio, onde procura viabilizar uma sociedade ou mercado de interesse, sendo este documento construído de forma antecipada. Este plano de negócio é independente, sendo assim não será vislumbrado um financiamento externo, mas um balizador para o empreendimento, ajudando no direcionamento de esforços de forma organizada, ordenada e sólida. O SEBRAE (2013) possui orientações em forma de proposta, que serve para a estruturação de um plano de negócios.

Quadro 02: Proposta de plano de negócios.

\begin{tabular}{|c|c|}
\hline Sumário executivo & $\begin{array}{l}\text { Contém o resumo dos principais pontos do plano de negócios, como dados dos } \\
\text { empreendedores, dados do empreendimento, missão da empresa, setores de } \\
\text { atividades, forma jurídica, enquadramento tributário, capital social e fonte de } \\
\text { recursos. }\end{array}$ \\
\hline Análise de mercado & $\begin{array}{l}\text { Esta etapa é dividida em três partes: o estudo dos clientes, concorrentes e } \\
\text { fornecedores. Sobre os clientes é importante identificar suas características gerais, } \\
\text { interesse e comportamento, e o que os leva ao ato da compra. No quesito } \\
\text { concorrentes, busca-se identificar a posição da empresa no mercado em relação } \\
\text { aos seus principais competidores, abordando questões como qualidade dos } \\
\text { produtos ou serviços, preço, localização, condições de pagamento oferecidas e } \\
\text { atendimento. Na parte sobre os fornecedores, buscará se identificar quem são, } \\
\text { onde estão, qualidade dos produtos e prazos de pagamento oferecidos. }\end{array}$ \\
\hline Plano de Marketing & $\begin{array}{l}\text { Deverá conter uma descrição dos principais produtos e serviços oferecidos, os } \\
\text { preços praticados, as estratégias promocionais a serem adotadas, a estrutura de } \\
\text { comercialização e a localização do negócio. }\end{array}$ \\
\hline Plano operacional & $\begin{array}{l}\text { Apresentação do layout, a capacidade produtiva/comercial/serviços, descrição dos } \\
\text { processos operacionais e a necessidade de pessoal. }\end{array}$ \\
\hline Plano financeiro & $\begin{array}{l}\text { Descrição da estimativa dos investimentos fixos, necessidade de capital de giro, } \\
\text { investimentos pré-operacionais, resumo dos investimentos totais, estimativa de } \\
\text { faturamento, estimativa de custo unitário, estimativa de custo de comercialização, } \\
\text { apuração dos custos diretos, estimativa dos custos de depreciação, demonstrativo } \\
\text { de resultados, indicadores de viabilidade, lucratividade, rentabilidade e prazo de } \\
\text { retorno do investimento. }\end{array}$ \\
\hline Construção de cenários & $\begin{array}{l}\text { Esta é a etapa posterior à finalização do plano de negócios, onde são construídos } \\
\text { tanto cenários pessimistas como otimistas. Também se pensam em ações para } \\
\text { evitar e prevenir-se frente às adversidades ou então para catalisar as situações } \\
\text { favoráveis. }\end{array}$ \\
\hline Avaliação estratégica & $\begin{array}{l}\text { Contempla uma análise das forças, oportunidades, fraquezas e ameaças (matriz } \\
\text { FOFA ou em inglês SWOT). }\end{array}$ \\
\hline $\begin{array}{c}\text { Avaliação do plano de } \\
\text { negócios }\end{array}$ & $\begin{array}{l}\text { Por ser o mapa de percurso, ele deve ser consultado e acompanhado } \\
\text { constantemente. Em função das flutuações a que o mercado está sujeito, ele } \\
\text { também deve ser revisado sempre que se julgar necessário, adaptando o seu } \\
\text { planejamento à nova realidade. }\end{array}$ \\
\hline
\end{tabular}

Fonte: Adaptado de SEBRAE (2013).

Vale lembrar que esse modelo é só uma proposta norteadora, e que existe uma estrutura específica para a construção de planos de negócios. Contudo, os documentos possuem um compromisso com o gestor, que é proporcionar um entendimento geral do negócio e como este será executado em maneira lógica. 


\section{Análise Estratégica}

A mesma importância dada ao plano de negócio poderá também ser atribuída a uma análise estratégica, bem detalhada do mercado que se deseja fixar. Para que seja possível compreender a evolução do conceito de estratégia, será necessário analisar a origem da palavra. Sendo assim "stratos" significando exército e "agein" comandar, originária da palavra estratégia, em sua etimologia a palavra passa a ideia de comando de exércitos (CHIAVENATO, 2014).

Por volta da metade do século XX a estratégia ganha relevância em relação ao contexto dos negócios, com grande a ajuda da obra Theory of games and economic behavior de John Von Newmann e Oskar Morgenstern, por permitir compreender comportamentos das pessoas em várias situações, além de resolução de problemas de naturezas distintas ao mesmo tempo (CHIAVENATO, 2014).

Em ideia geral a estratégia pode ser imaginada como um conjunto de ações ofensivas e/ou defensivas de forma competitiva, para que seja possível a obtenção de retornos financeiros em relação aos investimentos feitos, prosperando o negócio (PORTE, 1991).

A partir da definição de estratégias o desenvolvimento com bons resultados estarão balizados, possibilitando o crescimento sólido de forma consistente. A definição também permite que seja identificado o panorama do que pode influenciar o empreendimento no presente como no futuro, sendo consequência disso à sensibilização das oportunidades que o ambiente comercial promove circunstancialmente (PORTE, 1991).

Nesse sentido Nogueira e Almeida (2011) indicam ferramentas importantes auxiliar o processo de definição das estratégias, por exemplo, o modelo SWOT e as 05 Forças de Porter, como as duas ferramentas mais conhecidas no mundo.

Forças de Porter são caracterizadas como um modelo que exemplifica a análise setorial e abrangente para definir a estrutura do mercado em cinco forças competitivas e a relação entre estas, destacando o que uma organização deve executar para ser ou se manter competitiva. Porter (1991) propõe as forças da seguinte forma: Entrada de novos concorrentes, concorrentes existentes, produtos substitutos, barganha de compradores e barganha de fornecedores.

O modelo SWOT é uma ferramenta para auxílio no descobrimento de aspectos e características do ambiente interno e externo da empresa, analisando e fazendo combinações de pontos positivos com os negativos em relação às chances e perigos inerentes ao mercado de atuação. Nomes como Kenneth Andrews, Roland Christensen e Albert Humprey dividem os 
créditos pela autoria deste modelo, que também proporciona uma avaliação de situação, capacidade de competição dentro do mercado e planejamento estratégico. Assim provando ser uma ferramenta bastante importante para qualquer organização (CHIAVENATO, 2014).

\section{Setor Hoteleiro Brasileiro}

O serviço de hospedagem de indivíduos sempre existiu, visto que esta prática é realizada desde quando se tinha a necessidade de abrigar viajantes de constantes viagens pelo Brasil (PINHEIRO, 2002). Na realidade este serviço tornou-se mais sólido por meio da família real, trazendo tradições e costumes ingleses e franceses para o país (PEREIRA; COUTINHO, 2007).

O governo brasileiro ajudou de tal forma o setor, que foi criado o Decreto n. 1160, de 23 de Dezembro de 1907, cujo propunha aos cinco primeiros hotéis de grande porte, isenção de impostos durante sete anos. Conforme Caon (2008) os grandes cassinos, que possuíam hotéis no seu interior, inspirados nos cassinos americanos que foram construídos no Brasil, marcam um período chave para o setor hoteleiro, mas a proibição dos jogos de azar em 1946, forçaram os cassinos a fecharem as portas. E novamente por incentivos governamentais, maiores do que antes, houve uma recuperação do setor uma década depois.

Outro período destacado por Caon (2008) é o crescimento rápido com a chegada ao país de redes hoteleiras internacionais, que mesmo não sendo muitas, trouxeram novas ideias, novos serviços e preços. As vindas destas redes foram propiciadas pelo momento de desenvolvimento das estruturas de transporte aéreo e rodoviário na década de 1970.

\section{Metodologia}

Quanto o meio utilizado para este artigo utilizou-se de um estudo de opinião pública, por se tratar da buscar pelo conhecimento, pontos de vista e preferências que as pessoas têm sobre algum assunto, no âmbito organizacional esta pesquisa tem como objetivo auxiliar em tomadas de decisão (ALMEIDA, 1996).

A pesquisa fundamentou-se em fontes bibliográficas, por meio de livros. Caracteriza-se quanto aos procedimentos em pesquisa de campo, pois abrange o estudo de um ambiente por meio do levantamento de dados, sendo de cunho descritivo e exploratório, levando em 
consideração a busca por informações e discussões das eventualidades captadas (SEVERINO, 2016). A abordagem é quantitativa, pois se caracteriza em tabular e mensurar de maneira estatística, dados coletados em um ambiente delimitado, buscando opinião e conotações acerca de um fenômeno estudado (SEVERINO, 2016).

Para analisar a viabilidade da implantação do hotel, realizou-se um levantamento de dados na cidade de Missão Velha-CE, entre os dias 06 e 08 de novembro de 2018. A referida cidade possui uma população de 34.258 mil habitantes, confirmadas pelo último censo (IBGE, 2017). Como instrumento de coleta de dados aplicou-se um questionário, contendo 09 perguntas, distribuídas entre abertas e fechadas. O citado foi aplicado ao público pelo auxilio do Google Forms Questionários.

Participaram da pesquisa 101 pessoas, sendo estas 51\% do gênero masculino e $49 \%$ do feminino. A tabulação dos dados aconteceu por intermédio do software Excel. Em seguida foi realizada a análise e discussões dos resultados encontrados, visando obter a viabilidade do empreendimento que se almeja implantar.

\section{Análises e Discussões de Resultados}

Para saber a viabilidade sobre a implantação de um hotel na cidade de Missão VelhaCE, utilizou-se de uma pesquisa de opinião, com o objetivo de investigar a percepção do público a cerca do empreendimento em tese. Participaram da pesquisa 101 pessoas. Quanto ao gênero destas, estão representadas no gráfico 01.

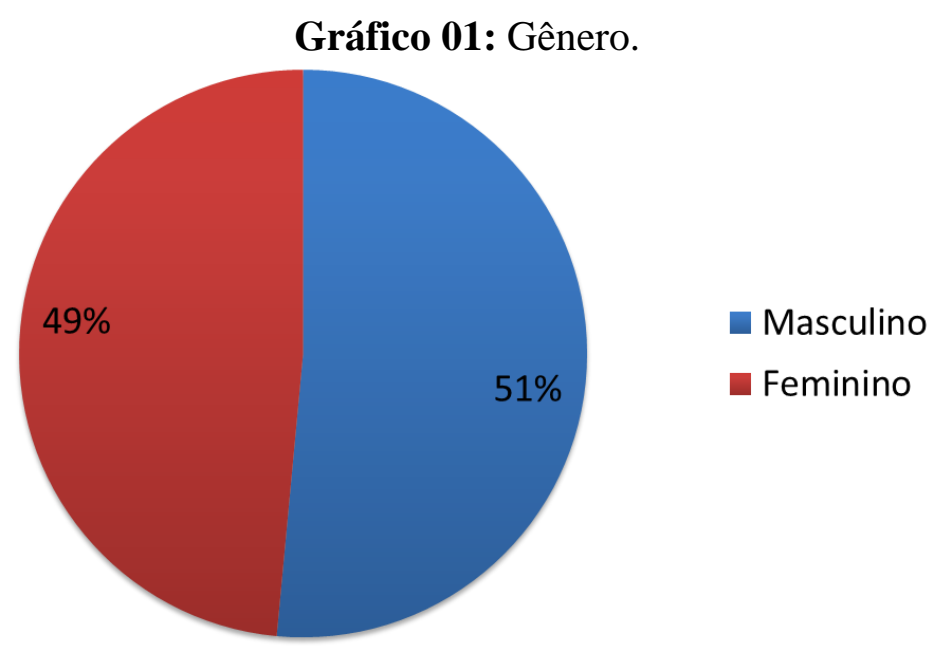

Fonte: Dados da Pesquisa (2018). 
No gráfico 01 está representado o gênero dos participantes, onde $51 \%$ responderam masculino e $49 \%$ falaram feminino. O percentual de um para outro é mínimo. No gráfico 02 contempla a faixa etária dos participantes da pesquisa.

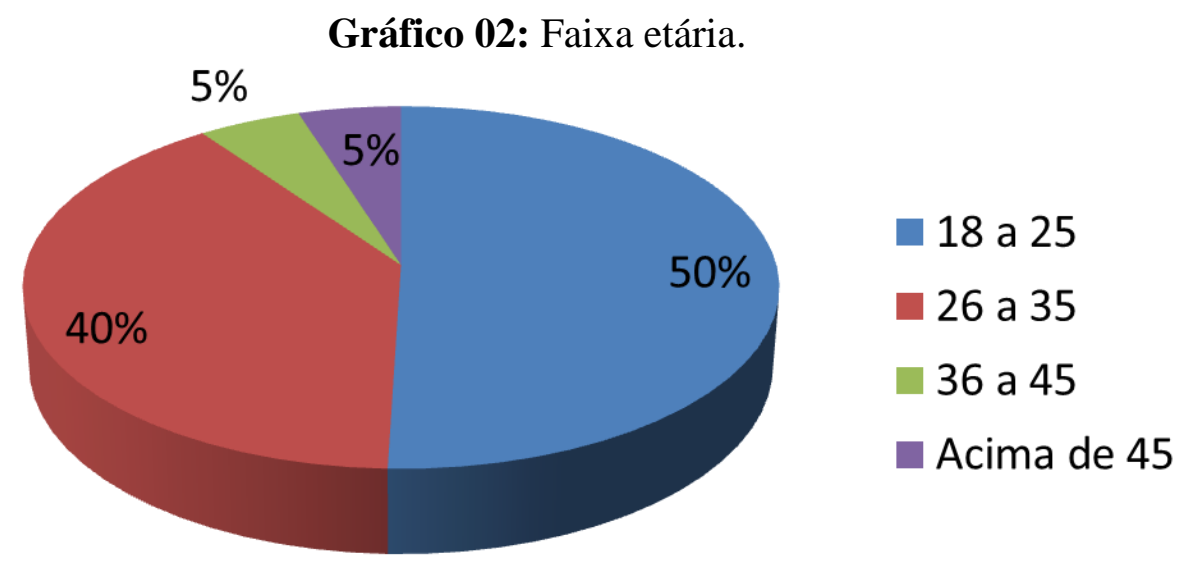

Fonte: Dados da Pesquisa (2018).

O gráfico 02 mostra a faixa etária do público participante da pesquisa, onde se observa que $50 \%$ afirmam possuir entre 18 a 25 anos. Em seguida $40 \%$ apontam ter entre 26 a 35 anos. E com idades entre 36 a 45 e acima de 45 anos, somam 10\%, visto 5\% respectivamente.

O gênero e a idade dos participantes podem gerar noções do perfil dos futuros clientes, levando em consideração a percepção, necessidade e opinião deste grupo, mediante a viabilidade do negócio em questão. Foi perguntado na sequência se estes já usaram do serviço de um hotel. Como resposta, percebeu-se que $92 \%$ já usaram ou utilizam de um hotel. $8 \%$ afirmam que nunca usaram nenhum tipo de serviço de hotel. Com este resultado, pode afirmar que os participantes em suam maioria, conhecem a natureza e o tipo de serviço ofertado pelo empreendimento referido.

Esse dado é de suma importância para os sócios, pois mostra que existe consumidores locais. O gráfico 03 apresenta a frequência com que o público utiliza de um hotel.

Gráfico 03: Frequência que utilizam de um hotel.

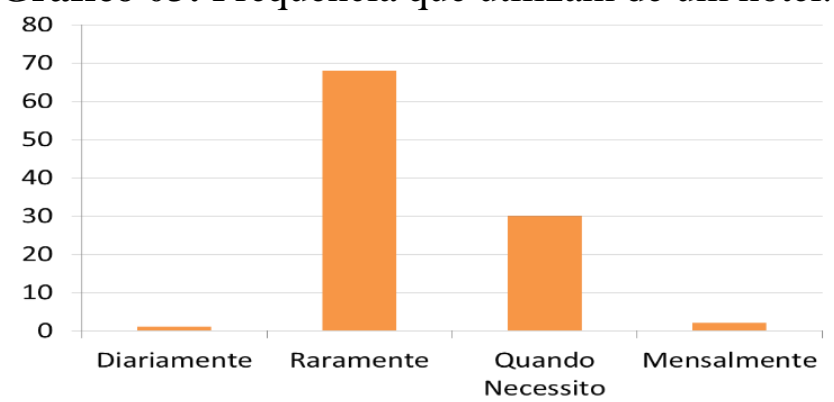

Fonte: Dados da Pesquisa (2018). 
É perceptível no gráfico 03 que há uma supremacia de participantes que frequentam raramente um hotel. Outros apontam "quando necessito uso o serviço de hotel". Estes dados apresentados estão relacionados à necessidade das pessoas, quando viajam, onde têm que utilizar de pousadas, hotéis ou dormitórios para passar geralmente as férias ou viagem de rotina e trabalho. De maneira leve, alguns falaram que diariamente ou mensalmente frequentam um hotel. Estas informações são relevantes para a viabilidade, tendo em vista o estudo turístico da região, para criar atrativos no setor hoteleiro para futuros clientes no período de férias, como menciona Caon (2008).

Gráfico 04: Opinião sobre a instalação de um hotel na cidade de Missão Velha-CE.

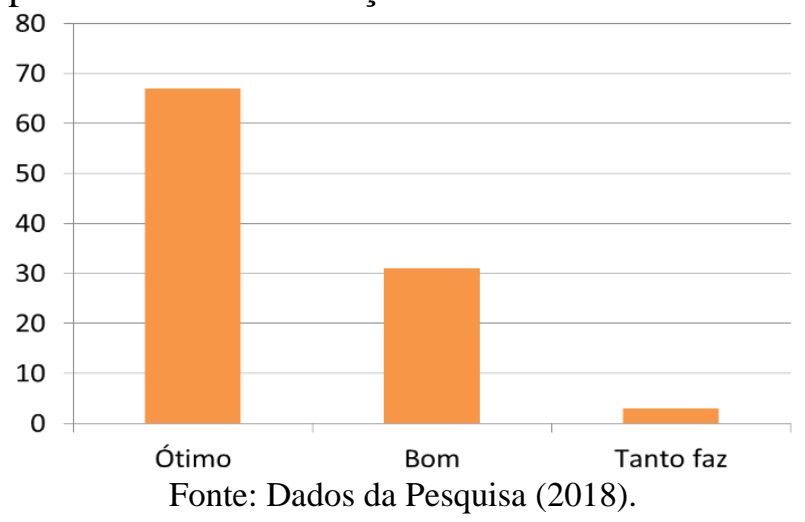

No gráfico 04 estão expressas as opiniões dos participantes acerca da instalação de um hotel na cidade de Missão Velha-CE. Percebe-se que a maioria considera a ideia de abertura do empreendimento "ótimo". Outra parte considerável da amostra aponta o negócio a ser iniciado como "bom". A aqueles que falaram "tanto faz", sendo estes em um numero menor, comparado aos demais. Vale ressaltar que esta última opinião se enquadra como um desprendimento do indivíduo com a ideia que se busca a viabilidade. Todavia, os resultados aqui destacados são viáveis para os sócios, visto o interesse positivo das pessoas pelo negócio.

Gráfico 05: O que consideram importante em um hotel.

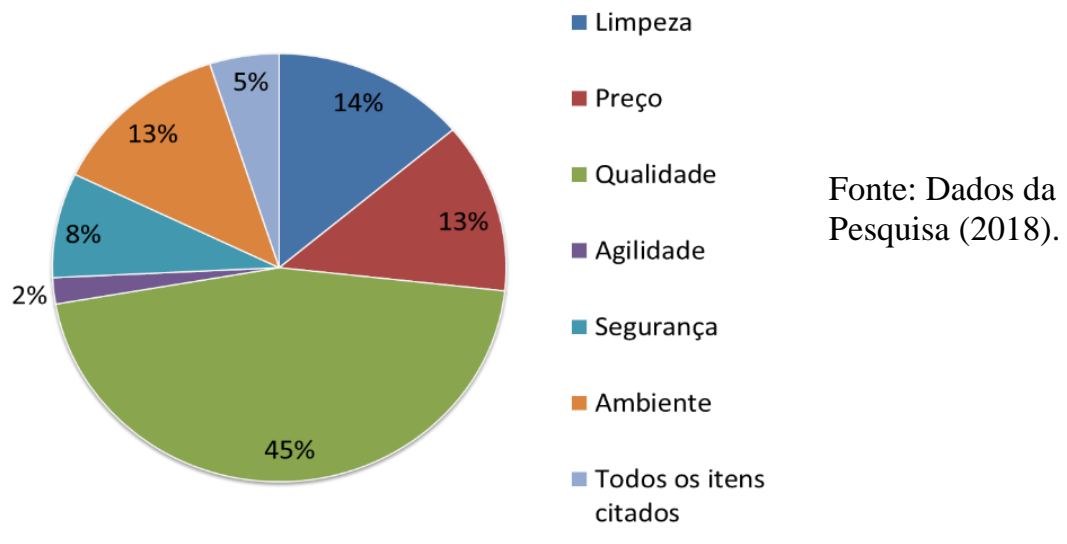


O gráfico 05 destaca os pontos considerados importantes em um hotel na opinião do público participante da pesquisa. É notório que existe uma supremacia do quesito qualidade com um percentual de $45 \%$. A limpeza com $14 \%$ é considerada um item importante. O preço e ambiente também são apontados, tendo um percentual de $13 \%$ respectivamente.

A segurança com $8 \%$ foi dita como um ponto importante. Apenas $2 \%$ citaram a agilidade nos serviços ofertados polo setor hoteleiro. 5\% afirmaram que todos os pontos citados são importantes. Estes dados fornecem aos sócios noções dos aspectos que os serviços e repartições/instalações do hotel deve apresentar e fornecer aos clientes da cidade de Missão Velha-CE. A prioridade deve ser a qualidade, pois foi o quesito citado com maior relevância.

A limpeza, segurança, ambiente e agilidade são quesitos indispensáveis a qualquer empreendimento, no ato de proporcionar comodidade e bem-estar aos consumidores. O preço por sua vez deverá ser formado mediante os custos e margem de lucro, sendo ainda conivente com as necessidades e capacidades financeiras do público-alvo escolhido. O gráfico 06 aponta os quesitos importantes para escolher um bom hotel.

Gráfico 06: Como escolhem um bom hotel.

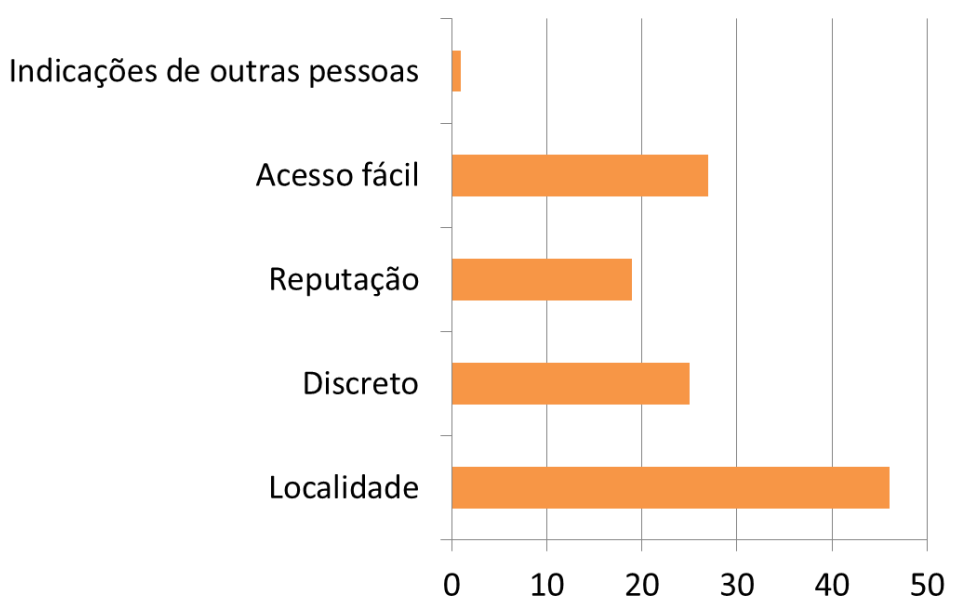

Fonte: Dados da Pesquisa (2018).

No gráfico 06 estão citados os pontos aos quais os indivíduos utilizam para escolher um bom hotel. É perceptível que a maioria destaca que escolhem pela localidade. Neste caso o local onde será instalado o negócio, deverá ser em um ponto estratégico para captar os clientes. Além de ter um fácil acesso e discreto, considerando as outras informações dadas pelos participantes. É notório que há um destaque para reputação, pelo fato dos consumidores optarem por hotéis renomados na prestação dos serviços e no excelente atendimento ao cliente. Alguns citam que escolhem por indicação de outras pessoas, através do tradicional marketing boca-a-boca. 
Gráfico 07: Busca por informações sobre um bom hotel.

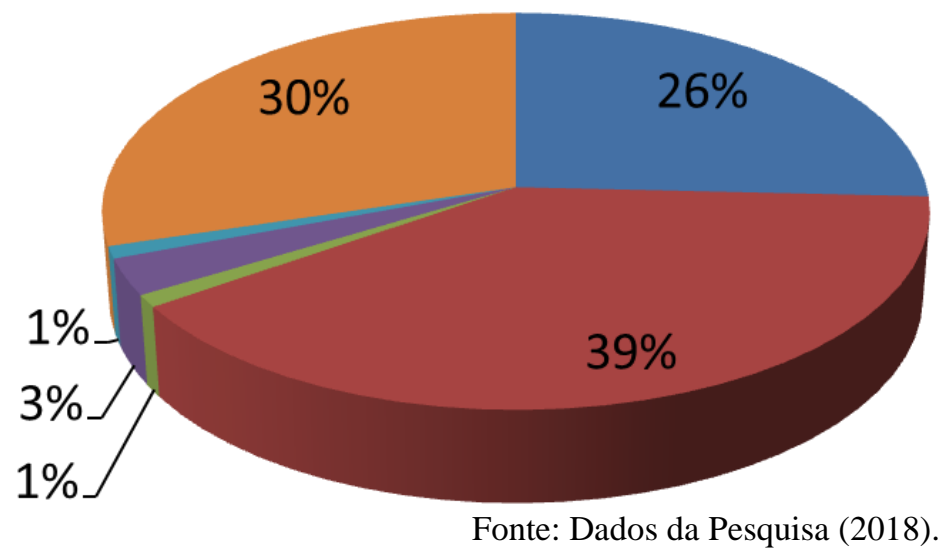

Sites

Redes sociais

TV

Rádio

Aplicativos

Boca-a-Boca

Com o gráfico 07 pode se avaliar as formas dos consumidores buscarem informações pertinentes sobre um bom hotel, podendo ser considerado canais de marketing. Na era da tecnologia e do domínio da internet, muitas empresas buscam realizar campanhas e propagandas em redes sociais ou site. No gráfico 07 conclui-se que 39\% das pessoas buscam informações sobre hotéis em redes sociais e $26 \%$ optam por sites. $30 \%$ utilizam o já tradicional e eficiente marketing boca-a-boca. 3\% falaram utilizar a rádio e 1\% em TV e aplicativos respetivamente.

Levando em conta estas informações, o marketing que poderá ser adotado pelos sócios do negócio será as redes sociais e sites de propagandas de hotelaria. Considerando o exposto no gráfico 06, a empresa quando instalada deverá manter os mais altos padrões de qualidade e comodidade para os clientes, a fim de obter uma excelente reputação, atingindo então o famoso marketing boca-a-boca.

O quadro 03 demostra alguns aspectos citados pelos participantes da pesquisa, como relevantes para o hotel em tese.

Quadro 03: Aspectos relevantes.

\begin{tabular}{|c|c|}
\hline Números de participantes & Aspectos relevantes \\
\hline 27 & Bom atendimento \\
\hline 05 & Comidas de qualidade \\
\hline 11 & Taxas diárias (preços) \\
\hline 26 & $\begin{array}{c}\text { Garagem com } \\
\text { cobertura }\end{array}$ \\
\hline 32 & Área para lazer \\
\hline
\end{tabular}

Fonte: Dados da Pesquisa (2018). 
No quadro 03 estão citados aspectos relevantes para um hotel, na opinião do público, sendo notório que a maioria almeja área para lazer, o que poderá ser o diferencial do hotel a ser implantado em Missão Velha-CE. De mesmo modo é apontado o desejo por garagem com cobertura. Bom atendimento também é questionado. Comidas de qualidade e taxas diárias são ditas como relevantes para ter no hotel.

As informações apresentadas no quadro 03 são grande importância para os sócios, visto que serão englobadas ao negócio, partindo do pressuposto do diferencial competitivo. A pesquisa como um todo acrescenta suporte para a validação da viabilidade na instalação do hotel, bem como a criação de aspectos inerentes e condizentes com as necessidades e desejos dos futuros clientes.

\section{Considerações Finais}

Com base na fundamentação teórica deste estudo e diante dos procedimentos teóricos e metodológicos utilizados, pode-se considerar que existe uma viabilidade positiva para se implantar um hotel na cidade de Missão Velha-CE.

A problemática deste estudo foi respondida ao identificar que há uma probabilidade do empreendimento em tese ser viável para os sócios. Em termos de objetivos é notório que falta desenvolver uma análise financeira, relacionado ao tempo de retorno do investimento e lucratividade. No entanto em termos econômicos para região e sócios, torna-se vantajoso.

Com o desenvolvimento da pesquisa foi possível observar que as pessoas procuram os serviços de um hotel raramente ou quando necessitam. Geralmente nas férias ou em viagens rotineiras a trabalho. Optam por hotéis que apresentem qualidade, limpeza, segurança, bom preço e ambiente agradável.

Ainda segundo as informações encontradas, o público da pesquisa escolhe um hotel pela localidade, com fácil acesso e que seja discreto. Ressaltando também a busca por aqueles que apresentem uma excelente reputação. A busca por informações de hotéis ocorre pelas redes sociais, sites de propagandas sobre hotelaria e pelo tradicional marketing boca-a-boca.

A maioria dos participantes já frequentou ou utilizou os serviços ofertados por um hotel. No entanto, estes pontuam que desejam bom atendimento, comidas de qualidade, taxas diárias (preços), garagem com cobertura e área para lazer das hotelarias. Estas informações são de grande relevância para os gestores, pois serão usadas como diferencial competitivo no mercado 
a ser atuado. Vale enfatizar que a maioria aponta a ideia de instalar um hotel na região (município de Missão Velha-CE) como “ótimo" e "bom”.

Por fim, com base nos resultados positivos da pesquisa, existe uma viabilidade na abertura do referido negócio na então cidade citada. Fica então aberta a necessidade de criar um plano financeiro, para fomentar a ideia e apresentar respaldo para o gerenciamento do empreendimento.

\section{Referências}

BERNARDI, L. A. Manual de Plano de Negócios: Fundamentos, Processos e Estruturação. São Paulo: Atlas, 2013.

CAON, M. Gestão Estratégica de Serviços de Hotelaria. São Paulo: Atlas, 2008.

CHIAVENATO, I. Introdução a Teoria Geral da Administração. 9. ed. Rio de Janeiro: Manole, 2014.

SEVERINO, Antônio Joaquim. Metodologia do Trabalho Científico. 24. ed. São Paulo: Cortez, 2016. Janeiro: Campus, v. 2, 2005.

Empreendedorismo. Transformando ideias em negócios. Rio de

DORNELAS, J. C. A. Empreendedorismo. Transformando ideias em negócios. Rio de Janeiro: Elsevier, v. 3, 2008.

HIRSCH, R.; PETERS, M. Empreendedorismo. Scielo Bookman, São Paulo, v. 44, n. 3, 2004. ISSN 126

IBGE. Estatísticas de empreendedorismo. Instituto Brasileiro de Geografia e Estatística. Rio de Janeiro, p. 1-93. 2017.

NOGUEIRA, C. R. D. A. T.; ALMEIDA, M. R. D. A. Plano de negócios e planejamento estratégico: ferramentas que geram vantagem competitiva. VIII Convibra Administração, 2011.

PEREIRA, F.; COUTINHO, H. Hotelaria: Da Era Antiga aos Dias Atuais. Revista Eletrônica Aboré, Manaus, n. 03, 2007. Disponivel em: <http://www.revistas.uea. edu.br/old/abore/artigos/artigos_3/Francisca\%20Felix\%20Pereira.pdf $>$. Acesso em 08 ago. 2018.

PINHEIRO, J. Hotelaria: Um Estudo de Caso da Rede Othon de Hotéis. Fundação Getúlio Vargas. Rio de Janeiro. 2002. 
PORTER, M. Estratégia competitiva: técnicas para análise das indústrias e da concorrência. 2. ed. Rio de Janeiro: Campus, v. 12, 1991.

SEBRAE. Como Elaborar um Plano de Negócios. Brasília. 2013.

SEBRAE. Sobrevivência das Empresas no Brasil. Serviço Brasileiro de Apoio às Micro e Pequenas Empresas. p. 76. Brasília. 2016.

\section{Como citar este artigo (Formato ABNT):}

SANTOS, Rozires Silva dos; VIANA; Wesley Barros; COSTA NETTO. Viabilidade para a Instalação de um Hotel em Missão Velha-CE. Id on Line Rev.Mult. Psic., 2018, vol.12, n.42, Supl. 1, p. 636650. ISSN: 1981-1179.

Recebido: $15 / 11 / 2018$

Aceito: $15 / 11 / 2018$ 